\title{
Simultaneous Quantification of Gallic Acid, Bergenin, Epicatechin, Epicatechin Gallate, Isoquercitrin, and Quercetin-3-Rhamnoside in Rat Plasma by LC-MS/MS Method and Its Application to Pharmacokinetics after Oral Administration of Ardisia japonica Extract
}

\author{
Xie-an Yu, ${ }^{1,2}$ John Teye Azietaku, ${ }^{1}$ Jin Li, ${ }^{1,2}$ Hui Wang, ${ }^{1}$ Fang Zheng, ${ }^{3}$ \\ Jia Hao, ${ }^{1,2}$ and Yan-xu Chang $\mathbb{D}^{1,2}$ \\ ${ }^{1}$ Tianjin State Key Laboratory of Modern Chinese Medicine, Tianjin University of Traditional Chinese Medicine, Tianjin 300193, China \\ ${ }^{2}$ Key Laboratory of Formula of Traditional Chinese Medicine, Tianjin University of Traditional Chinese Medicine, \\ Ministry of Education, Tianjin 300193, China \\ ${ }^{3}$ School of Integrative Medicine, Tianjin Traditional Medical University, Tianjin 300193, China
}

Correspondence should be addressed to Yan-xu Chang; tcmcyx@126.com

Received 4 September 2017; Accepted 5 December 2017; Published 14 January 2018

Academic Editor: Tadaaki Satou

Copyright (C) 2018 Xie-an Yu et al. This is an open access article distributed under the Creative Commons Attribution License, which permits unrestricted use, distribution, and reproduction in any medium, provided the original work is properly cited.

Ardisia japonica is a well-known traditional Chinese medicinal herb used as a diuretic, for treating cough and for stopping uterine bleeding. A simple, sensitive, and reliable LC-MS/MS method was developed to determine six active compounds in rat plasma and this method was further applied to the pharmacokinetic study of these compounds after oral administration of Ardisia japonica extract. Acetonitrile was used to precipitate the protein in the plasma samples. Using acetonitrile and formic acid aqueous solution $(0.05 \%)$ as the mobile phase, the separation of the six compounds and internal standards was achieved at a flow rate of $300 \mu \mathrm{L} \mathrm{min}{ }^{-1}$ on an Eclipse plus $\mathrm{C}_{18}$ column at an elution time of $16 \mathrm{~min}$. A tandem mass spectrometer having an electrospray ionization (ESI) source was used in the detection of the analytes and internal standards using multiple reactions monitoring (MRM) in the negative ionization mode. The LLOQ was 2, 2, 4, 2, 1, and $0.4 \mathrm{ng} \mathrm{mL}^{-1}$ for gallic acid, bergenin, epicatechin, epicatechin gallate, isoquercitrin, and quercetin-3-rhamnoside, respectively. The validated method was applied to the pharmacokinetic study of gallic acid, bergenin, and quercetin-3-rhamnoside in rat plasma after oral administration of $A$. japonica extract to rats.

\section{Introduction}

Ardisia japonica (Thunb.) Bl, a low growing shrub belonging to the family Myrsinaceae, is one of the well-known traditional medicinal traditional herbs being probably one of the most studied among over 500 other species. It is referred to as "Ai di cha" in Chinese and is very famous for its use in treating various respiratory tract infections such as pneumonia, bronchitis, and tuberculosis. It has also been widely used in treating asthma and conjunctivitis and possesses bacteriostatic and hemostatic effects [1-3].
Some phytochemicals having been isolated and identified in A. japonica include coumarins, flavonoids, quinones, and saponins. Examples of these phytochemicals are 2-hydroxy5-methoxy-pentadecenyl-benzoquione, ardisin, ardisinol I and II, bergenin, embelin, ilexol, myricitrin, quercetin, quercetrin, rapanone, and ardisianones $\mathrm{A}$ and $\mathrm{B}$ [2, 46]. They elicit pharmacological activities such as antiinflammatory [4], antioxidant [7, 8], anticancer [9], anti-HIV $[5,10]$, and antidiabetic [6] effects. In an investigation to compare the bioactivities of six species of Ardisia on human hepatoma (HepG2) cells in vitro, it was observed that the 
TABLE 1: MRM parameters of six compounds and three ISs.

\begin{tabular}{|c|c|c|c|c|c|c|}
\hline Compounds & Q1 & Q3 & $\mathrm{DP}(\mathrm{V})$ & $\mathrm{EP}(\mathrm{V})$ & $\mathrm{CE}(\mathrm{V})$ & $\mathrm{CXP}(\mathrm{V})$ \\
\hline Gallic acid & 168.8 & 124.9 & -28 & -9 & -20 & -5 \\
\hline Bergeninum & 327.0 & 191.9 & -48 & -8 & -38 & -5 \\
\hline Epicatechin & 288.9 & 108.9 & -45 & -4.5 & -35 & -4 \\
\hline Epicatechin gallate & 441.1 & 169.2 & -55 & -8 & -28 & -3.5 \\
\hline Isoquercitrin & 462.9 & 300.0 & -80 & -8 & -38 & -6.5 \\
\hline Quercetin-3-rhamnoside & 447.0 & 300.0 & -60 & -4.5 & -35 & -8 \\
\hline Ferulic acid (IS1) & 192.8 & 134.1 & -28 & -9 & -24 & -5 \\
\hline Puerarin (IS2) & 415.0 & 266.9 & -62 & -8 & -45 & -6.5 \\
\hline Warfarin (IS3) & 307.0 & 161.1 & -41 & -9 & -27 & -7 \\
\hline
\end{tabular}

chemical constituents in A. japonica and two other species elicited the greatest inhibitory potential against liver cancer cells. On the other hand, few methods have been developed on the pharmacokinetic of these components present in $A$. japonica.

A number of analytical methods have been previously developed in determining the chemical constituents in $A$. japonica. They include TLC-densitometric method used in determining bergenin content [11] and HPLC $[12,13]$. Few analytes were determined in A. japonica from the methods listed above and hence may not be representative of the various types of compounds present in this herb. Besides, these methods present with long retention times and are less sensitive in the determination of the various components in this herb. Also, from our search into various literatures on this herb, no pharmacokinetic study has been conducted on this herb to the best of our knowledge.

In this study, a simple, sensitive, reliable, and validated LC-MS-MS method was presented for the simultaneous determination of six compounds in rat plasma and subsequent application to a pharmacokinetic study of these analytes after oral administration of the A. japonica extract to rats.

\section{Materials and Methods}

2.1. Materials and Reagents. Standards including six analysis compounds (gallic acid, bergenin, epicatechin, epicatechin gallate, isoquercitrin, and quercetin-3-rhamnoside) and three internal standards (ISs) (ferulic acid, puerarin, and warfarin) (Figure 1) were purchased from National Institute for the Chinese National Institute of Control of Pharmaceutical and Biological Products (Beijing, China). Acetonitrile and methanol (Fisher, Fair Lawn, USA) and formic acid (Tedia, Fairfield, USA) were of HPLC grade. Other reagents were of analytical grade. The TCM, A. japonica, was offered by Anguo TCM market (Hebei, China).

2.2. Chromatographic and Mass Spectrometry Conditions. The LC-MS/MS system consisted of an Agilent 1200 system coupled with a binary pump (G1312A), an autosampler (G13678), a vacuum degasser (G1322A), and an API 3200 triple quadrupole mass spectrometer with an ESI source.
An Eclipse plus C18 column $(4.6 \mathrm{~mm} \times 100 \mathrm{~mm}, 1.8 \mu \mathrm{m})$ was maintained at $35^{\circ} \mathrm{C}$ and used for the separation with the mobile phase, comprising acetonitrile (A) and formic acid aqueous solution $(0.05 \%)$, using a gradient elution of $25 \%-25 \%$ A (0-8 min), 25\%-90\% A (8-14 min), and $90 \%-95 \%$ A (14-16 min). The flow rate was set at $300 \mu \mathrm{L}$ $\mathrm{min}^{-1}$ and the inject volume was $10 \mu \mathrm{L}$.

The analytes were determined in negative mode and quantified by multiple-reaction monitoring (MRM) mode. The source parameters were as follows: curtain gas, 25 psi; collision gas, 12 psi; ion spray voltage, $-4500 \mathrm{~V}$; temperature, $500^{\circ} \mathrm{C}$; ion source gas $1,45 \mathrm{psi}$; and ion source gas $2,55 \mathrm{psi}$, respectively. The source parameters of every compound were optimized and are listed in Table 1. Data acquisition was operated by Analyst 1.4.2 software (AB Sciex).

2.3. Preparation of the A. japonica Extract. For the preparation of the plant extract, $1 \mathrm{~kg} A$. japonica was extracted by refluxing with $95 \%$ ethanol for $2 \mathrm{~h}$. The filtrate was concentrated using a rotary evaporator under reduced pressure. The extract yield was $8.9 \%$.

2.4. Preparation of Stock Solution, Calibration Standards, and Quality Control (QC) Samples. The standard stock solutions of gallic acid, bergenin, epicatechin, epicatechin gallate, isoquercitrin, and quercetin-3-rhamnoside were prepared by dissolving each separately in methanol to achieve a concentration of $1 \mathrm{mg} \mathrm{mL}^{-1}$ for use as the stock solution. The three ISs including ferulic acid, puerarin, and warfarin were prepared using the same procedure as mentioned above with the concentration being $1 \mu \mathrm{g} \mathrm{mL}^{-1}$. Calibration standard solutions were prepared by spiking the different concentrations of the standard mixture working solutions into plasma to achieve the concentration range of $2-500 \mathrm{ng} \mathrm{mL}^{-1}$ for gallic acid; 2-500 $\mathrm{ng} \mathrm{mL}^{-1}$ for bergenin; 4-1000 $\mathrm{ng} \mathrm{mL}^{-1}$ for epicatechin; 2-500 ng mL ${ }^{-1}$ for epicatechin gallate; $1-250 \mathrm{ng} \mathrm{mL}^{-1}$ for isoquercitrin; and $0.4-100 \mathrm{ng} \mathrm{mL}^{-1}$ for quercetin-3rhamnoside. The QC samples were prepared by spiking $10 \mu \mathrm{L}$ of the standard stock solutions into $100 \mu \mathrm{L}$ of blank plasma to achieve LLOQ, low, medium and high concentrations of 2, 6, 20 , and $200 \mathrm{ng} \mathrm{mL}^{-1}$ for gallic acid; 2, 6, 20, and $200 \mathrm{ng} \mathrm{mL}^{-1}$ for bergenin; 4, 12, 40, and $400 \mathrm{ng} \mathrm{mL}^{-1}$ for epicatechin; 2, 
<smiles>O=C(O)c1cc(O)c(O)c(O)c1</smiles>

Gallic acid<smiles>COc1c(O)cc2c(c1O)[C@H]1O[C@H](CO)[C@@H](O)[C@H](O)[C@H]1OC2=O</smiles>

Bergeninum<smiles>Oc1cc(O)c2c(c1)OC(c1ccc(O)c(O)c1)C(O)C2</smiles>

L-Epicatechin<smiles>O=C(O[C@@H]1Cc2c(O)cc(O)cc2O[C@H]1c1ccc(O)c(O)c1)c1cc(O)c(O)c(O)c1</smiles>

(-)-Epicatechin gallate<smiles>COc1cc(/C=C/C(=O)O)ccc1O</smiles>

Ferulic acid (IS1)<smiles>O=c1c(O[C@@H]2O[C@H](CO)[C@@H](O)[C@H](O)[C@H]2O)c(-c2ccc(O)c(O)c2)oc2cc(O)cc(O)c12</smiles>

Isoquercitrin<smiles>O=c1c(-c2ccc(O)cc2)coc2c(O[C@@H]3O[C@H](CO)[C@@H](O)[C@H](O)[C@H]3O)c(O)ccc12</smiles>

Puerarin (IS2)<smiles>C[C@@H]1O[C@@H](Oc2c(-c3ccc(O)c(O)c3)oc3cc(O)cc(O)c3c2=O)[C@H](O)[C@@H](O)[C@@H]1O</smiles>

Quercetin-3rhamnoside

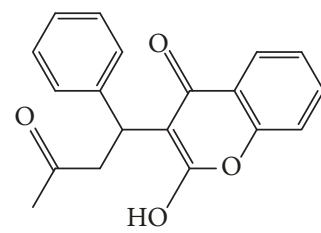

Warfarin (IS3)

FIgURE 1: Chemical structures of 6 components and 3 ISs.

6, 20, and $200 \mathrm{ng} \mathrm{mL}^{-1}$ for epicatechin gallate; $1,3,10$, and $100 \mathrm{ng} \mathrm{mL}^{-1}$ for isoquercitrin; and $0.4,1.2,4$, and $40 \mathrm{ng} \mathrm{mL}^{-1}$ for quercetin-3-rhamnoside.

2.5. Preparation of Plasma Samples. $100 \mu \mathrm{L}$ of plasma sample, $10 \mu \mathrm{L}$ of the IS solutions, and $10 \mu \mathrm{L}$ of $30 \%$ formic acid were added to the tube. Samples were vortex-mixed for $1 \mathrm{~min}$, and $400 \mu \mathrm{L}$ of acetonitrile was then used in precipitating the protein, after which they were centrifuged for $10 \mathrm{~min}$ at $14,000 \mathrm{rpm}$. The supernatant was transferred into another centrifuge tube and evaporated using nitrogen gas to dryness. The dried residue was reconstituted using $100 \mu \mathrm{L}$ of methanol. The sample was further shaken and ultrasonicated for $2 \mathrm{~min}$ to ensure that it was well dissolved. It was subsequently centrifuged at 14,000 rpm for $10 \mathrm{~min}$, and $10 \mu \mathrm{L}$ aliquot of the solution was injected into the LC-MS/MS system for analysis.

\subsection{Method Validation}

2.6.1. Selectivity and the Lower Limit of Quantification (LLOQ). The method selectivity was tested by comparing the chromatograms of six different batches of blank rat plasma samples with plasma spiked with LLOQ concentration samples of the 6 compounds and plasma samples obtained after oral administration of $A$. japonica extracts.

The lower limit of quantification (LLOQ) was calculated by the signal-to-noise ratio $(\mathrm{S} / \mathrm{N})$ higher than 5 through analyzing the 6 standards spiked in plasma samples. Validation of the method was done in accordance with the guidelines set by the United States Food and Drug Administration (USFDA) [14].

2.6.2. Linearity. An eight-point standard calibration curve was constructed by using the peak area ratio of 6 analysis compounds to the IS against concentration. Each calibration curve was performed individually by using least square weighted $(1 / x)$ linear regression. The calibration curve was applied to evaluated intraday (on the same day), interday (on three consecutive days), and stability accuracies and precision of the assay.

2.6.3. Precision and Accuracy. Testing of the precision and accuracy was performed using the six batches of QC samples at four different concentrations during 1 day for intraday 

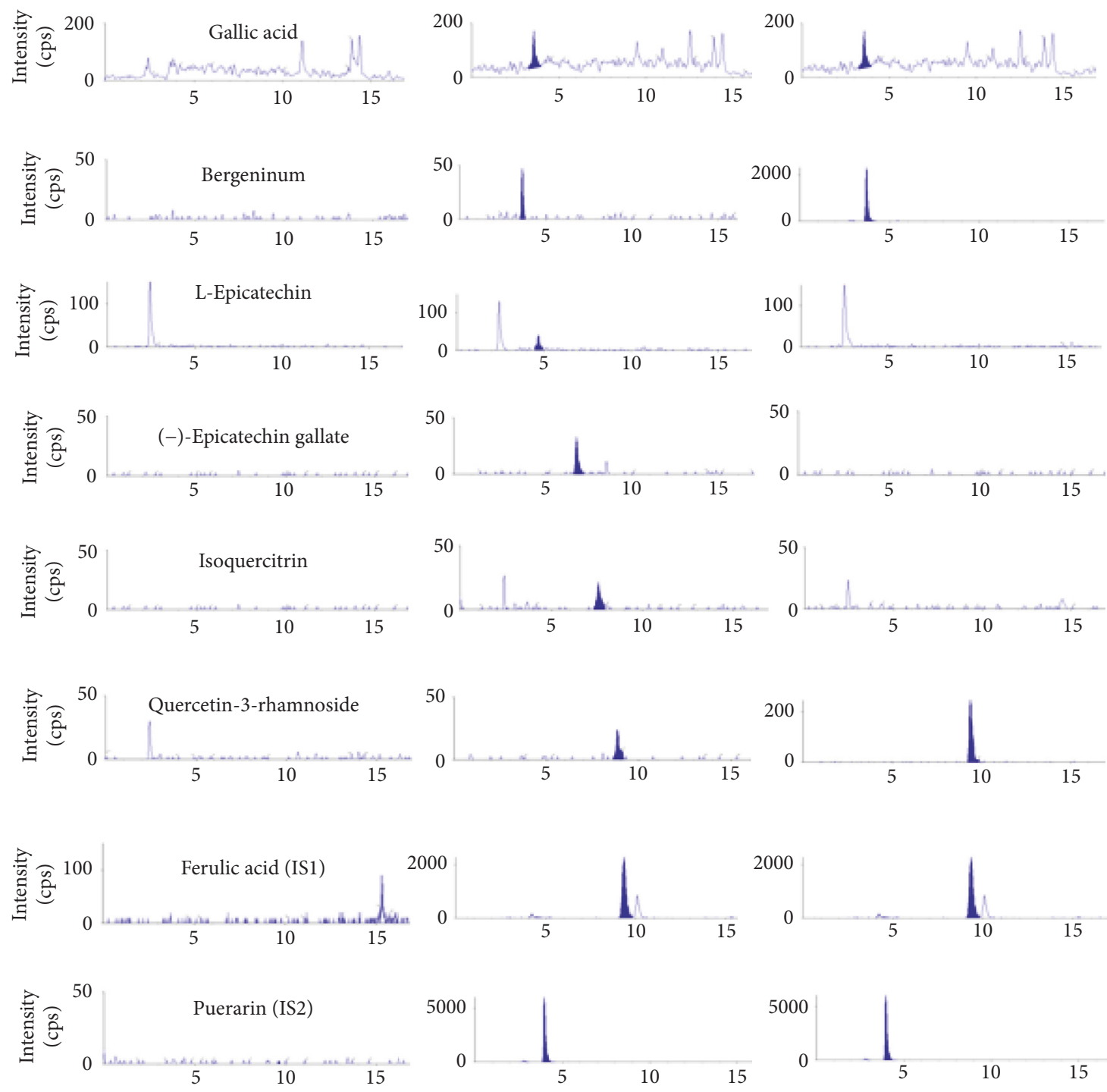

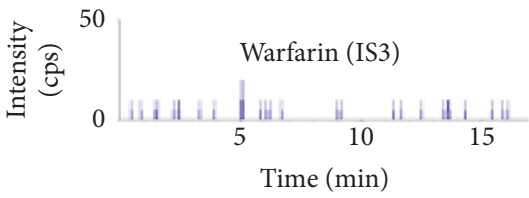

(a)

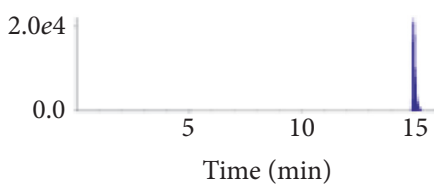

(b)

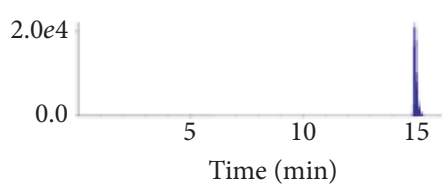

(c)

FIgURE 2: Typical chromatograms of (a) blank rat plasma, (b) blank rat plasma spiked with standard compounds at LLOQs, and (c) real sample from rats at $30 \mathrm{~min}$ after oral administration of $A$. japonica extract.

TABLE 2: The calibration curves, linearity range, and LLOQs of 6 compounds $(n=6)$.

\begin{tabular}{|c|c|c|c|c|}
\hline Compounds & Regression equation & $R$ & Linearity range & LLOQ $\left(\mathrm{ng} \mathrm{ml}^{-1}\right)$ \\
\hline Gallic acid & $Y=0.0157 X-0.0112$ & 0.9920 & $2-500$ & 2 \\
\hline Bergeninum & $Y=0.00125 X+0.000782$ & 0.9983 & $2-500$ & 2 \\
\hline Epicatechin & $Y=0.00223 X+0.00102$ & 0.9984 & $4-1000$ & 4 \\
\hline Epicatechin gallate & $Y=0.00579 X-0.00933$ & 0.9940 & $2-500$ & 2 \\
\hline Isoquercitrin & $Y=0.00582 X+0.00202$ & 0.9964 & $1-250$ & 1 \\
\hline Quercetin-3-rhamnoside & $Y=0.0156 X-0.000007$ & 0.9971 & $0.4-100$ & 0.4 \\
\hline
\end{tabular}


TABLE 3: Intraday, interday accuracy, and precision of 6 compounds $(n=6)$.

\begin{tabular}{|c|c|c|c|c|c|}
\hline \multirow{2}{*}{ Compounds } & \multirow{2}{*}{ Concentration $(\mathrm{ng} / \mathrm{mL})$} & \multicolumn{2}{|c|}{ Intraday } & \multicolumn{2}{|c|}{ Interday } \\
\hline & & Accuracy (\%) & RSD (\%) & Accuracy (\%) & RSD (\%) \\
\hline \multirow{4}{*}{ Gallic acid } & 2 & 99.4 & 6.59 & 96.0 & 9.67 \\
\hline & 6 & 93.8 & 9.14 & 101 & 9.12 \\
\hline & 20 & 85.5 & 4.33 & 86.1 & 7.57 \\
\hline & 200 & 104 & 3.87 & 108 & 7.31 \\
\hline \multirow{4}{*}{ Bergeninum } & 2 & 106 & 9.08 & 103 & 16.2 \\
\hline & 6 & 100 & 10.7 & 99 & 10.4 \\
\hline & 20 & 114 & 6.40 & 108 & 11.4 \\
\hline & 200 & 109 & 13.4 & 111 & 13.2 \\
\hline \multirow{4}{*}{ L-Epicatechin } & 4 & 92.8 & 5.07 & 96.5 & 12.2 \\
\hline & 12 & 97.3 & 8.15 & 88.9 & 12.9 \\
\hline & 40 & 94.9 & 9.63 & 96.3 & 12.8 \\
\hline & 400 & 90.0 & 15.7 & 94.8 & 9.62 \\
\hline \multirow{4}{*}{$(-)$-Epicatechin gallate } & 2 & 93.4 & 16.0 & 108 & 9.97 \\
\hline & 6 & 93.9 & 7.11 & 94.6 & 15.8 \\
\hline & 20 & 86.6 & 12.2 & 90.0 & 14.3 \\
\hline & 200 & 103 & 10.7 & 98.9 & 13.8 \\
\hline \multirow{4}{*}{ Isoquercitrin } & 1 & 110 & 9.45 & 104 & 12.4 \\
\hline & 3 & 90.3 & 7.54 & 92.4 & 13.4 \\
\hline & 10 & 101 & 11.8 & 101 & 8.50 \\
\hline & 100 & 109 & 4.59 & 102 & 8.10 \\
\hline \multirow{4}{*}{ Quercetin-3-rhamnoside } & 0.4 & 89.1 & 14.9 & 91.4 & 15.6 \\
\hline & 1.2 & 85.6 & 4.42 & 87.9 & 11.8 \\
\hline & 4 & 95.7 & 14.7 & 90.1 & 12.5 \\
\hline & 40 & 99.9 & 5.01 & 95.0 & 8.05 \\
\hline
\end{tabular}

and within 3 different days for interday. The accuracy and precision were calculated and expressed as the percentage of the measured concentration to the nominal concentration and relative standard deviation (RSD), respectively. The range of the testing should be $85-115 \%$ for the accuracy, and the RSD at each concentration level should not exceed $15 \%$ of the coefficient of variation (CV) except for the LLOQ, where it should not exceed $20 \%$ of the CV.

2.6.4. Recovery and Matrix Effect. Determination of the recovery was carried on through comparing the peak areas of 6 compounds extracted spiked samples with those of the analytes and IS without extraction at correspondent concentrations. The matrix effect was investigated by analytes in postextracted spiked samples with those of the analytes in unextracted samples, at the same concentrations at QC concentrations. The mean value of the recovery and matrix effect should be in the range of $85-115 \%$ at three levels of QC sample except for the LLOQ, where it should be in the range of $80-120 \%$.

2.6.5. Stability. The stability for 6 analysis compounds including $24 \mathrm{~h}$ stability (keeping the sample in autosampler conditions of room temperature for $24 \mathrm{~h}$ ), three freeze/thaw cycles (subjected to 3 cycles of freezing at about $-20^{\circ} \mathrm{C}$ and thawing at room temperature), and a long-term stability (stored at about $-80^{\circ} \mathrm{C}$ for 4 weeks) of analytes in plasma was performed by analyzing QC samples at four different concentrations.

2.7. Pharmacokinetic Study. Ten male Sprague-Dawley rats (270-280 g) were kept at the animal center of Tianjin University of Traditional Chinese Medicine (Tianjin, China) under environmentally controlled conditions. The room temperature of the animal center was maintained at $25^{\circ} \mathrm{C}$ and the rats were allowed free access to food and water although only water was offered to rats $12 \mathrm{~h}$ prior to the experiment. According to the clinical dose used in human, the rat dose of A. japonicae extracts used was $0.93 \mathrm{~g} \mathrm{~kg}^{-1}$. After oral administration of the extract to rat, $200 \mu \mathrm{L}$ of blood samples was obtained into heparinized $1.5 \mathrm{~mL}$ polythene tubes at 5,10 , 15,30 , and $45 \mathrm{~min}$ and $1,2,4,6,8,12$, and $24 \mathrm{~h}$. After blood sample collection into the heparinized $1.5 \mathrm{~mL}$ polythene tubes and centrifugation at $6000 \mathrm{rpm}$ for $10 \mathrm{~min}$, the plasma was transferred into clean tubes and stored in a freezer at $-20^{\circ} \mathrm{C}$ until analysis. The pharmacokinetic parameters were determined using pharmacokinetics program (DAS1.0 
TABLE 4: The recoveries and matrix effects of 6 compounds $(n=6)$.

\begin{tabular}{|c|c|c|c|c|c|}
\hline \multirow{2}{*}{ Compounds } & \multirow{2}{*}{ Concentration (ng/mL) } & \multicolumn{2}{|c|}{ Recovery } & \multicolumn{2}{|c|}{ Matrix effect } \\
\hline & & Accuracy (\%) & RSD (\%) & Accuracy (\%) & RSD (\%) \\
\hline \multirow{4}{*}{ Gallic acid } & 2 & 111 & 10.2 & 116 & 8.89 \\
\hline & 6 & 111 & 6.76 & 113 & 3.52 \\
\hline & 20 & 104 & 7.92 & 110 & 5.03 \\
\hline & 200 & 106 & 8.50 & 99.7 & 9.08 \\
\hline \multirow{4}{*}{ Bergeninum } & 2 & 109 & 8.59 & 109 & 2.31 \\
\hline & 6 & 108 & 12.6 & 112 & 14.2 \\
\hline & 20 & 95.4 & 7.14 & 107 & 6.05 \\
\hline & 200 & 91.0 & 10.2 & 115 & 9.46 \\
\hline \multirow{4}{*}{ L-Epicatechin } & 4 & 111 & 13.7 & 99.5 & 8.46 \\
\hline & 12 & 105 & 11.3 & 102 & 11.6 \\
\hline & 40 & 110 & 11.1 & 88.5 & 5.87 \\
\hline & 400 & 92.4 & 6.49 & 92.0 & 6.95 \\
\hline \multirow{4}{*}{$(-)$-Epicatechin gallate } & 2 & 109 & 6.58 & 113 & 10.4 \\
\hline & 6 & 108 & 9.99 & 114 & 5.67 \\
\hline & 20 & 109 & 9.76 & 108 & 7.24 \\
\hline & 200 & 101 & 5.08 & 115 & 13.5 \\
\hline \multirow{4}{*}{ Isoquercitrin } & 1 & 103 & 10.2 & 112 & 1.72 \\
\hline & 3 & 90.0 & 12.3 & 106 & 13.3 \\
\hline & 10 & 107 & 8.03 & 113 & 8.65 \\
\hline & 100 & 98.3 & 5.63 & 113 & 6.28 \\
\hline \multirow{4}{*}{ Quercetin-3-rhamnoside } & 0.4 & 104 & 10.9 & 110 & 10.1 \\
\hline & 1.2 & 108 & 13.6 & 110 & 11.8 \\
\hline & 4 & 89.6 & 3.14 & 110 & 11.9 \\
\hline & 40 & 97.9 & 3.59 & 118 & 6.77 \\
\hline Ferulic acid & 100 & 80.0 & 2.76 & 87.7 & 3.10 \\
\hline Puerarin & 100 & 85.7 & 6.55 & 79.4 & 2.65 \\
\hline Warfarin & 100 & 76.4 & 3.77 & 106 & 3.41 \\
\hline
\end{tabular}

Medical College of Wannan, China) and performing a one compartmental analysis.

\section{Results and Discussion}

3.1. LC-MS/MS Optimization. The MS intensities for the 6 compounds and 3 ISs were optimized following infusion of standard solution of each into the mass spectrometer. The signal intensities of the compounds were found to be greater in the negative modes after optimizing each compound in both positive and negative modes. Deprotonated $[\mathrm{M}-\mathrm{H}]^{-}$ parent ions were produced from the full scan Q1 mass spectrum for the 6 compounds and 3 ISs at $m / z$ 168.8, 327.0, $288.9,441.1,462.9,447.0,192.8,415.0$, and 307.0 for gallic acid, bergenin, epicatechin, epicatechin gallate, isoquercitrin, and quercetin-3-rhamnoside, ferulic acid (IS1), puerarin (IS2), and warfarin (IS3), respectively. The MS parameters were optimized such as the DP and CE to ensure that MRM transitions were sensitive. The various MRM parameters are listed in Table 1. IS1 and IS3 were used to determine gallic acid and bergenin, respectively. IS2 was selected to determine the four components including epicatechin, epicatechin gallate, isoquercitrin, and quercetin-3-rhamnoside.

Various mobile phases consisting of different solutions of acetonitrile, methanol, and formic acid were optimized in order to obtain short run times, well-resolved peaks, and peaks with symmetrical shape. In the end, better response, good separation, and increased sensitivity of the compound peaks were obtained using a mobile phase consisting of acetonitrile and $0.05 \%$ aqueous formic acid solution. Also, no interference was observed between the tested compounds and internal standards. Typical chromatograms of blank plasma, plasma spiked with the compounds and IS, and plasma with the IS are shown in Figure 2.

\subsection{Method Validation}

3.2.1. Specificity. The method's specificity was evaluated by looking at the MRM chromatograms of blank plasma sample, blank plasma spiked with reference standards, and IS and then plasma sample after giving $A$. japonica extract orally to rats as shown in Figure 2. A good separation of 
TABLE 5: Stability of the 6 compounds $(n=6)$.

\begin{tabular}{|c|c|c|c|c|c|c|c|}
\hline \multirow{2}{*}{ Compounds } & \multirow{2}{*}{ Concentration $(\mathrm{ng} / \mathrm{mL})$} & \multicolumn{2}{|c|}{24 h stability } & \multicolumn{2}{|c|}{ Free-throw 3 times } & \multicolumn{2}{|c|}{ Long stability (1 month) } \\
\hline & & Accuracy (\%) & RSD (\%) & Accuracy (\%) & RSD (\%) & Accuracy (\%) & RSD (\%) \\
\hline \multirow{4}{*}{ Gallic acid } & 2 & 116 & 8.59 & 92.5 & 9.19 & 95.6 & 11.4 \\
\hline & 6 & 111 & 7.23 & 114 & 8.03 & 101 & 7.64 \\
\hline & 20 & 85.8 & 3.54 & 94.0 & 7.77 & 98.4 & 5.65 \\
\hline & 200 & 103 & 4.32 & 101 & 10.6 & 92.7 & 7.51 \\
\hline \multirow{4}{*}{ Bergeninum } & 2 & 83.4 & 14.4 & 106 & 5.81 & 82.3 & 11.4 \\
\hline & 6 & 105 & 9.58 & 104 & 12.3 & 91.3 & 16.4 \\
\hline & 20 & 92.5 & 13.3 & 94.0 & 4.95 & 112 & 9.97 \\
\hline & 200 & 106 & 8.45 & 87.3 & 10.9 & 114 & 7.59 \\
\hline \multirow{4}{*}{ Epicatechin } & 4 & 91.8 & 4.22 & 105 & 12.6 & 114 & 6.65 \\
\hline & 12 & 95.1 & 10.6 & 111 & 7.78 & 104 & 7.25 \\
\hline & 40 & 96.6 & 9.33 & 111 & 7.27 & 113 & 9.54 \\
\hline & 400 & 97.6 & 4.69 & 99.4 & 2.79 & 102 & 4.47 \\
\hline \multirow{4}{*}{ Epicatechin gallate } & 2 & 108 & 5.75 & 109 & 11.7 & 87.1 & 6.45 \\
\hline & 6 & 100 & 11.9 & 98.4 & 7.56 & 88.9 & 10.8 \\
\hline & 20 & 85.3 & 3.72 & 91.4 & 3.89 & 100 & 7.17 \\
\hline & 200 & 89.7 & 6.01 & 88.0 & 6.78 & 105 & 4.88 \\
\hline \multirow{4}{*}{ Isoquercitrin } & 1 & 111 & 6.64 & 105 & 13.0 & 109 & 11.9 \\
\hline & 3 & 99.1 & 11.8 & 103 & 9.81 & 100 & 9.45 \\
\hline & 10 & 96.7 & 5.57 & 96.9 & 3.54 & 99.9 & 6.89 \\
\hline & 100 & 92.9 & 4.54 & 91.0 & 6.77 & 91.3 & 8.75 \\
\hline \multirow{4}{*}{ Quercetin-3-rhamnoside } & 0.4 & 93.7 & 9.37 & 115 & 3.67 & 114 & 8.76 \\
\hline & 1.2 & 96.3 & 7.49 & 90.4 & 8.84 & 92.2 & 7.77 \\
\hline & 4 & 93.3 & 9.24 & 93.3 & 3.98 & 90.6 & 8.70 \\
\hline & 40 & 87.3 & 5.65 & 85.0 & 4.94 & 85.0 & 6.51 \\
\hline
\end{tabular}

TABLE 6: The pharmacokinetic parameters of 3 compounds.

\begin{tabular}{lccc}
\hline Parameters & Gallic acid & Bergeninum & Quercetin-3-rhamnoside \\
\hline$T \max (\mathrm{h})$ & $1.40 \pm 1.13$ & $0.86 \pm 0.52$ & $0.50 \pm 0.60$ \\
$C \max (\mathrm{ng} / \mathrm{mL})$ & $35.5 \pm 10.2$ & $288 \pm 107$ & $7.08 \pm 8.28$ \\
$T_{1 / 2}(\mathrm{~h})$ & $3.21 \pm 4.56$ & $3.87 \pm 1.62$ & $2.59 \pm 2.80$ \\
$\mathrm{AUC}_{(0-24 \mathrm{~h})}(\mathrm{ng} / \mathrm{mL} * \mathrm{~h})$ & $194.4 \pm 44.0$ & $1743 \pm 666$ & $6.44 \pm 12.00$ \\
$\mathrm{AUC}_{(0-\infty)}(\mathrm{ng} / \mathrm{mL} * \mathrm{~h})$ & $199.7 \pm 43.9$ & $1841 \pm 769$ & $6.95 \pm 20.67$ \\
$\mathrm{MRT}_{\left(0-t_{24 \mathrm{~h}}\right)}(\mathrm{h})$ & $4.50 \pm 1.15$ & $6.04 \pm 1.05$ & $5.08 \pm 6.36$ \\
$\mathrm{MRT}_{(0-\infty)}(\mathrm{h})$ & $5.33 \pm 1.61$ & $7.26 \pm 2.17$ & $7.09 \pm 19.6$ \\
\hline
\end{tabular}

the 6 compounds was achieved without interference peaks from endogenous substances at retention times of gallic acid (4.2 $\mathrm{min})$, bergenin $(4.6 \mathrm{~min})$, epicatechin $(4.9 \mathrm{~min})$, (-)-epicatechin gallate $(7.2 \mathrm{~min})$, isoquercitrin $(8.4 \mathrm{~min})$, and quercetin-3-rhamnoside $(9.5 \mathrm{~min})$.

3.2.2. Linearity and Sensitivity. The calibration curves for the 6 compounds were linear within the stipulated ranges as shown in Table 2. This was achieved with the help of weighted least square linear regression analysis with a weight factor of $1 / x$. Representative mean calibration curves are as follows: $Y=0.0157 X-0.0112, Y=0.00125 X+0.000782, Y=$ $0.00223 X+0.00102, Y=0.00579 X-0.00933, Y=0.00582 X+$ 0.00202 , and $Y=0.0156 X-0.000007$ for gallic acid, bergenin, epicatechin, epicatechin gallate, isoquercitrin, and quercetin3-rhamnoside, respectively, where $y$ represented the peak area ratio of analytes to IS and $x$ denoted the concentration of analytes present in the plasma samples. Also, the LLOQs of the analytes are $2,2,4,2,1$, and $0.4 \mathrm{ng} \mathrm{mL}^{-1}$ for gallic acid, bergenin, epicatechin, epicatechin gallate, isoquercitrin, and quercetin-3-rhamnoside, respectively. LLOQs of these analytes were sufficiently applied for the pharmacokinetic study in rats.

3.2.3. Precision and Accuracy. The intraday and interday variabilities of the LLOQ and QC samples are shown in Table 3. The intraday and interday precision ranged from 3.87 to $15.7 \%$ and 7.31 to $16.2 \%$, respectively, while data on the accuracy was in the range of 85.5 to $114 \%$. All assay values were within stipulated limits and hence suggestive of a reliable, reproducible, and accurate method.

3.2.4. Extraction Recovery and Matrix Effect. As shown in Table 4 , the extraction recovery of the analytes was in the range of $89.6 \%$ to $111 \%$ at three concentration levels. On the other hand, the matrix effects of the six compounds at three 

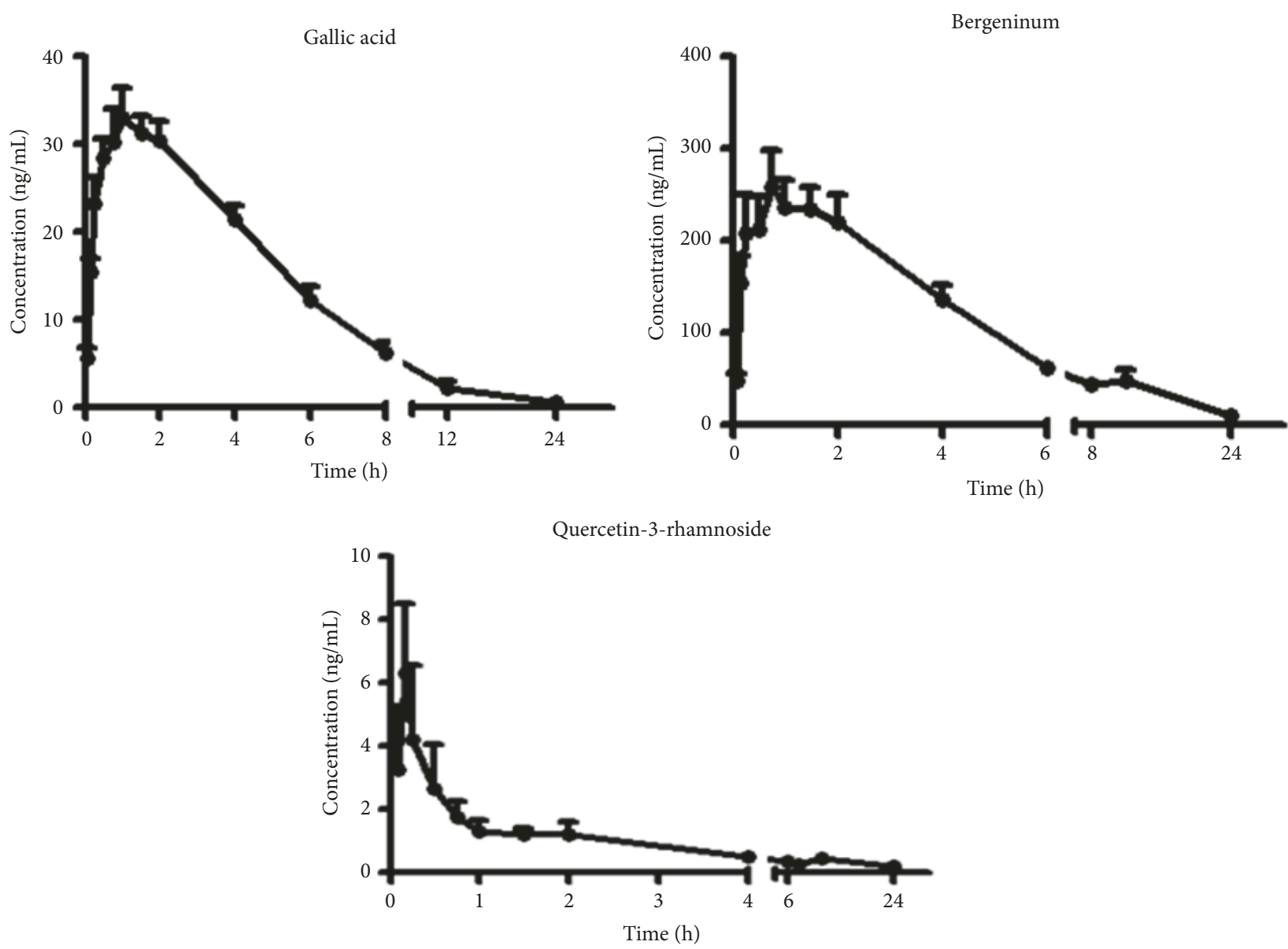

Figure 3: Mean plasma concentration-time profiles of gallic acid, bergenin, and quercetin-3-rhamnoside in rats after oral administration of A. japonica extract $(n=10$, mean $\pm \mathrm{SD})$.

concentration levels ranged from $88.5 \%$ to $116 \%$. No significant matrix effects on analytes and IS were observed. This indicates that there are no coeluting substances influencing the ionization of the analytes and IS and the good protein precipitation efficiency.

3.2.5. Stability. The stabilities of all analytes were tested through the analysis of the three levels of QC samples as shown in Table 5. It was found that the analytes were considerably stable in rat plasma and processed samples under different storage conditions.

\subsection{The Content of 6 Compounds in A. japonica Extract.} The six compounds were determined in A. japonica extract. The content of gallic acid, bergenin, epicatechin, epicatechin gallate, isoquercitrin, and quercetin-3-rhamnoside are $2.1467 \mu \mathrm{g} / \mathrm{mg}, 24.9 \mu \mathrm{g} / \mathrm{mg}, 0.696 \mu \mathrm{g} \mathrm{mg}^{-1}, 0.198 \mu \mathrm{g} \mathrm{mg}^{-1}$, $0.0916 \mu \mathrm{g} \mathrm{mg}^{-1}$, and $2.13 \mu \mathrm{g} \mathrm{mg}^{-1}$, respectively. Therefore, the administration dosages of gallic acid, bergenin, epicatechin, epicatechin gallate, isoquercitrin, and quercetin3-rhamnoside after administration of $A$. japonica extract were $2.00 \mathrm{mg} \mathrm{kg}^{-1}, 23.16 \mathrm{mg} \mathrm{kg}^{-1}, 0.65 \mathrm{mg} \mathrm{kg}^{-1}, 0.18 \mathrm{mg} \mathrm{kg}^{-1}$, $0.09 \mathrm{mg} \mathrm{kg}^{-1}$, and $1.98 \mathrm{mg} \mathrm{kg}^{-1}$, respectively.

3.4. Application. The method having been validated was successfully applied to the determination of plasma concentration of 3 of the compounds in rats, after oral administration of $A$. japonica extract at a dose of $0.93 \mathrm{~g} \mathrm{~kg}^{-1}$ to rats. The 3 compounds including gallic acid, bergenin, and quercetin-3-rhamnoside were determined and their plasma concentration-time profiles are illustrated in Figure 3. Their one compartment model pharmacokinetic parameters are shown in Table 6. Gallic acid reached a peak plasma concentration of $35.5 \pm 10.2 \mathrm{ng} \mathrm{mL}^{-1}$ and the Tmax was $1.40 \pm$ $1.13 \mathrm{~h}$ after oral administration of the $A$. japonica extract. The area under the curve $\left(\mathrm{AUC}_{0-24 \mathrm{~h}}\right)$ and the half-life, $T_{1 / 2}$, were $194 \pm 44 \mathrm{ng}(\mathrm{mL} \mathrm{h})^{-1}$ and $3.21 \pm 4.57 \mathrm{~h}$, respectively. The Cmax and Tmax for bergenin and quercetin-3-rhamnoside were $288 \pm 107 \mathrm{ng} \mathrm{mL}^{-1}, 0.86 \pm 0.52 \mathrm{~h}$ and $7.08 \pm 8.28 \mathrm{ng} \mathrm{mL}^{-1}$ and $0.50 \pm 0.60 \mathrm{~h}$ with the area under the curve for each compound being $1743 \pm 666 \mathrm{ng}(\mathrm{mL} \mathrm{h})^{-1}$ and $6.44 \pm 11.99 \mathrm{ng}(\mathrm{mL} \mathrm{h})^{-1}$, respectively. Both compounds exhibited a Tmax less than one hour implying that they had a fast rate of absorption 
into plasma from the gastrointestinal tract after oral administration, compared to gallic acid which achieved maximum plasma concentrations after one hour.

\section{Conclusions}

A sensitive and simple LC-MS/MS method for simultaneous measurement of 6 compounds in rat plasma was developed and subsequently validated. The method proved to be accurate, precise, and specific and was successfully applied to investigate the pharmacokinetics of gallic acid, bergenin, and quercetin-3-rhamnoside after an oral administration of $A$. japonica extracts to rats.

\section{Ethical Approval}

All applicable institutional guidelines for the care and use of animals were followed.

\section{Conflicts of Interest}

All authors declare that there are no conflicts of interest.

\section{Authors' Contributions}

John Teye Azietaku and the first author contributed equally to this study.

\section{Acknowledgments}

This research was supported by the National Natural Science Foundation of China (81374050 and 81503213), Special Program of Talents Development for Excellent Youth Scholars in Tianjin, Science and Technology Basic Work of Science and Technology (2014FY111100), and PCSIRT (IRT-14R41).

\section{References}

[1] W. Tang and G. Eisenbrand, Ardisia japonica (Thunb.) Bl, Chinese Drugs of Plant Origin: Chemistry, Pharmacology, and Use in Traditional and Modern Medicine, Springer, Berlin, Germany, 1992.

[2] H. Kobayashi and E. De Mejía, "The genus Ardisia: A novel source of health-promoting compounds and phytopharmaceuticals," Journal of Ethnopharmacology, vol. 96, no. 3, pp. 347-354, 2005.

[3] Anonymous, "Experimental studies on Ardisia japonica in the treatment of chronic bronchitis," Zhonghua yi xue za zhi, vol. 12, pp. 706-710, 1973.

[4] Y. Fukuyama, Y. Kiriyama, J. Okino et al., "Naturally Occurring 5-Lipoxygenase Inhibitor. II. Structures and Syntheses of Ardisianones A and B, and Maesanin, Alkenyl-1,4benzoquinones from the Rhizome of Ardisia japonica," Chemical \& Pharmaceutical Bulletin, vol. 41, no. 3, pp. 561-565, 1993.

[5] S. Piacente, C. Pizza, and N. De Tommasi, "Constituents of Ardisia japonica and their in vitro anti-HIV activity," Journal of Natural Products, vol. 59, no. 6, pp. 565-569, 1996.

[6] Y.-F. Li, L.-H. Hu, F.-C. Lou, J. Li, and Q. J. Shen, "PTP1B inhibitors from Ardisia japonica," Journal of Asian Natural Products Research, vol. 7, no. 1, pp. 13-18, 2005.
[7] A. M. B. Newell, G. G. Yousef, M. A. Lila, M. V. Ramírez-Mares, and E. G. de Mejia, "Comparative in vitro bioactivities of tea extracts from six species of Ardisia and their effect on growth inhibition of HepG2 cells," Journal of Ethnopharmacology, vol. 130, no. 3, pp. 536-544, 2010.

[8] H. Fenglin, L. Ruili, H. Bao, and M. Liang, "Free radical scavenging activity of extracts prepared from fresh leaves of selected Chinese medicinal plants," Fitoterapia, vol. 75, no. 1, pp. 14-23, 2004.

[9] X. Chang, W. Li, Z. Jia, T. Satou, S. Fushiya, and K. Koike, "Biologically active triterpenoid saponins from Ardisia japonica," Journal of Natural Products, vol. 70, no. 2, pp. 179-187, 2007.

[10] N. T. Dat, K. Bae, A. Wamiru et al., "A dimeric lactone from Ardisia japonica with inhibitory activity for HIV-1 and HIV-2 ribonuclease H," Journal of Natural Products, vol. 70, no. 5, pp. 839-841, 2007.

[11] W. Liu, "Quantitative analysis of bergenin in herba Ardisia japonica Bl by TLC-densitometric method," China journal of Chinese materia medica, vol. 16, no. 102, pp. 102-104, 1991.

[12] L.-K. Song and W.-M. Zhou, "Content determination of bergenin in Ardisia pusilla by HPLC," Journal of Chinese Medicinal Materials, vol. 30, no. 4, pp. 422-423, 2007.

[13] C. Y. Xu, L. Y. Zhang, Y. Wang, S. H. Wei, R. G. Qin, and M. Y. Chi, "Study on HPLC fingerprint of miao medicine Ardisia japonica," Journal of Chinese Medicinal Materials, vol. 37, pp. 1570-1573, 2014.

[14] Guidance for Industry, Analytical Procedures and Methods Validation for Drugs and Biologics, US Department of Healthy and Services, Food and Drug Administration, CDER, Rockville, USA, 2015. 


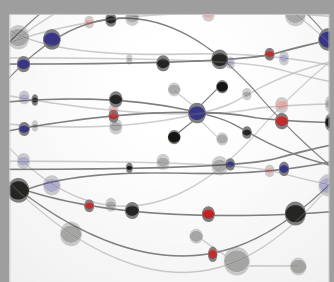

The Scientific World Journal
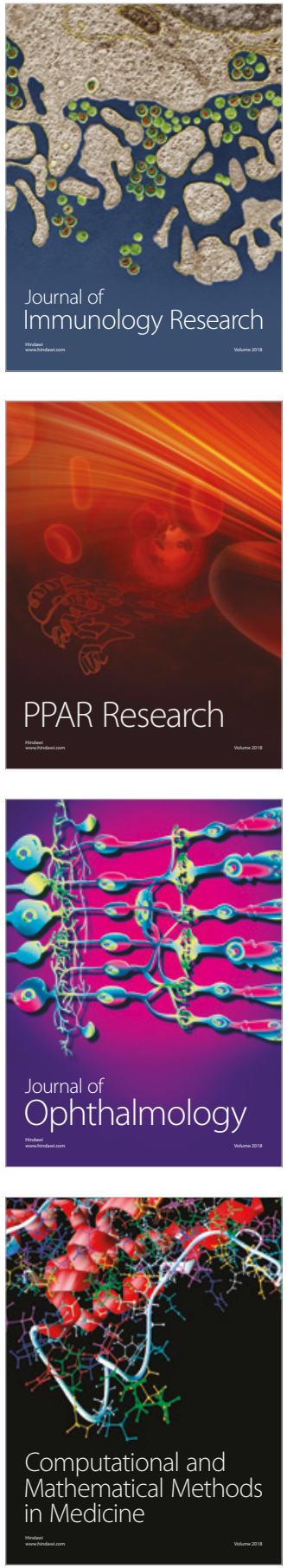

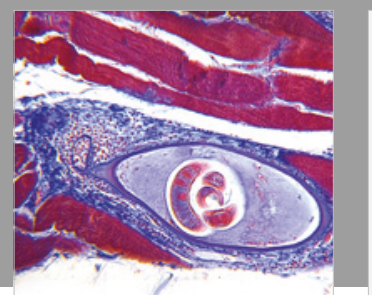

Gastroenterology Research and Practice

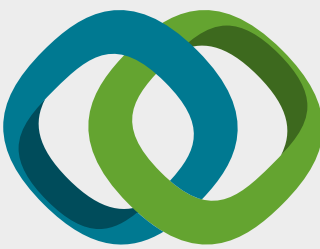

\section{Hindawi}

Submit your manuscripts at

www.hindawi.com
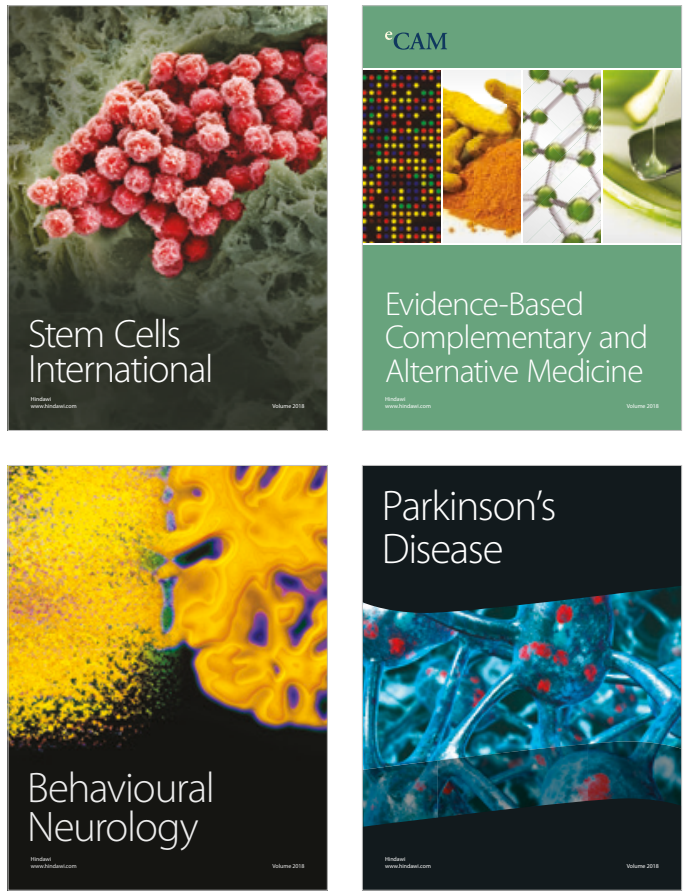

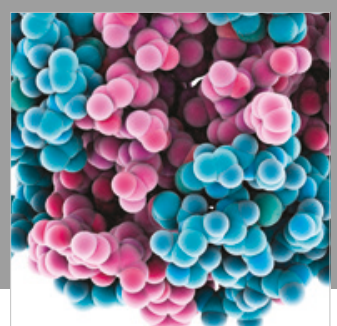

ournal of

Diabetes Research

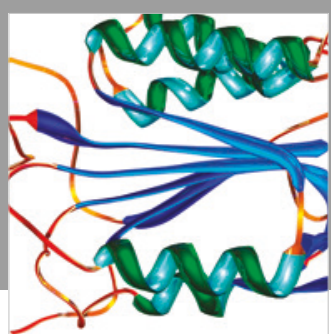

Disease Markers
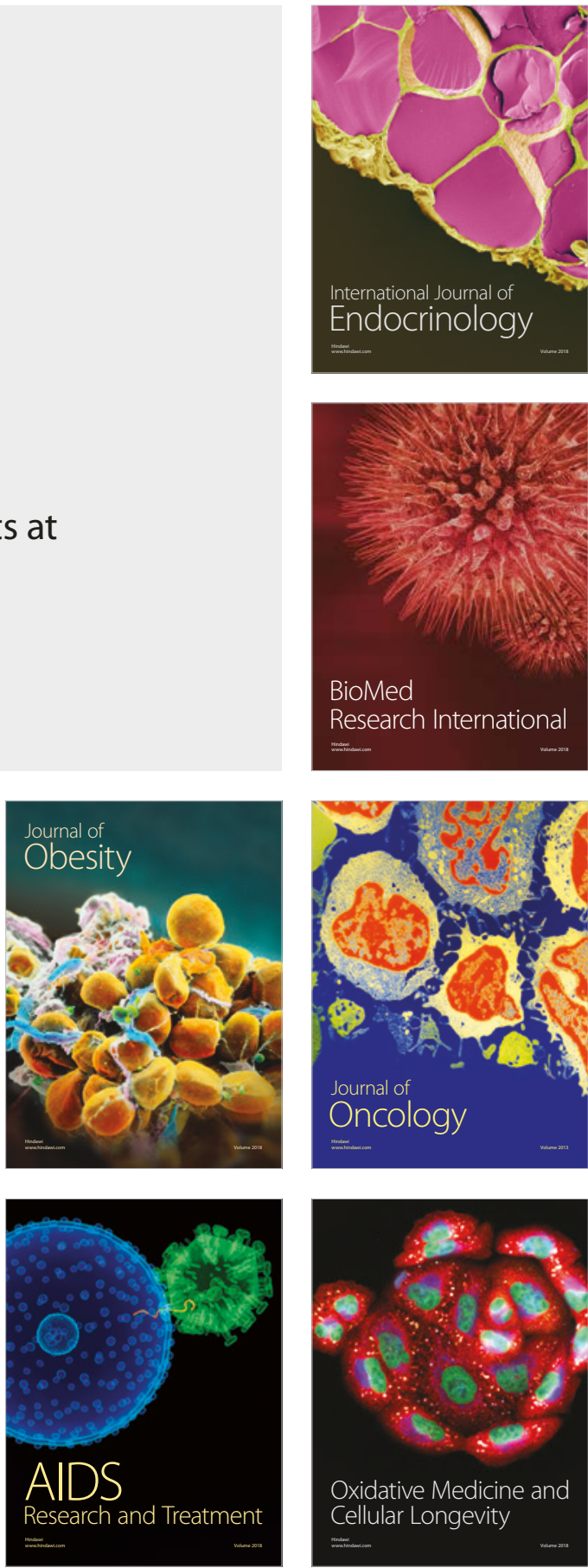